\title{
Efficient gene delivery in differentiated human embryonic stem cells
}

\author{
Jae-Hwan Kim ${ }^{1,2}$, Hyun-Jin Do ${ }^{1}$, \\ Seong-Jun Choi ${ }^{1,2}$, Hyun-Jung Cho ${ }^{1}$, \\ Kyu-Hyung Park ${ }^{2}$, Heung-Mo Yang ${ }^{1}$, \\ Sang-Hwa Lee ${ }^{1,2}$, Dong-Ku Kim ${ }^{1,2}$, \\ KyuBum Kwack ${ }^{2}$, Sun-Kyung $\mathrm{Oh}^{3}$, \\ Shin-Yong Moon ${ }^{3}$, Kwang-Yul Cha ${ }^{1,2}$ \\ and Hyung-Min Chung ${ }^{1,2,4}$
}

${ }^{1}$ Cell and Gene Therapy Research Institute

${ }^{2}$ Graduate School of Life Science and Biotechnology

Pochon CHA University

${ }^{3}$ Stem Cell Research Center

Seoul National University, Seoul, South Korea

${ }^{4}$ Corresponding author: Tel, 82-2-3468-3391;

Fax, 82-2-3468-3373; E-mail, hmchung@chacares.com

Accepted 25 January 2005

Abbreviations: AFP, $\alpha$-fetoprotein; CBA, chicken $\beta$ actin; CMV, cytomegalo-virus; EB, embryoid body; EC cell, embryonic carcinoma cell; ES cell, embryonic stem cell; $h E F 1 \alpha$, human cellular polypeptide chain elongation factor $1 \alpha$; SSEA, stage specific embryonic antigen

\begin{abstract}
Human embryonic stem (hES) cells are capable of differentiating into pluralistic cell types, however, spontaneous differentiation generally gives rise to a limited number of specific differentiated cell types and a large degree of cell heterogeneity. In an effort to increase the efficiency of specified hES cell differentiation, we performed a series of transient transfection of hES cells with EGFP expression vectors driven by different promoter systems, including human cellular polypeptide chain elongation factor 1 alpha (hEF1 $\alpha$ ), human cytomegalo-virus, and chicken $\beta$-actin. All these promoters were found to lead reporter gene expression in undifferentiated hES cells, but very few drug-selectable transfectants were obtained and failed to maintain stable expression of the transgene with either chemical or electroporation methods. In an attempt to increase transfection efficiency and obtain stable transgene expression, differentiated hES cells expressing both mesodermal and ectodermal mar-
\end{abstract}

kers were derived using a defined medium. Differentiated hES cells were electroporated with a hEF1 $\alpha$ promoter-driven EGFP or human noggin expression vector. Using RT-PCR, immunocytochemistry and fluorescence microscopy, the differentiated hES cells transfected with foreign genes were confirmed to retain stable gene and protein expression during prolonged culture. These results may provide a new tool for introducing exogenous genes readily into hES cells, thereby facilitating more directed differentiation into specific and homogenous cell populations.

Keywords: differentiation; embryoid body; human embryonic stem cell; promoter; RT-PCR; transfection

\section{Introduction}

Human embryonic stem ( $h E S$ ) cells, derived from the inner cell mass of blastocysts, possess pluripotentials to grow infinitely and to differentiate into various cell types (Thomson et al., 1998). Their pluripotency is useful for studying critical cell developmental stages and may eventually have clinical application, for example in regenerative medicine (Gropp et al., 2003). In mouse ES (mES) cells, many strategies have been developed to induce efficient differentiation into specific cell lineages. These include the use of defined culture conditions that employ various cytokines, growth or extracellular matrix factors (Loebel et al., 2003; Sachinidis et al., 2003; Takahashi et al., 2003). However, because ES cells tend to proliferate and differentiate in a rather heterogeneous manner, cells induced to differentiate by exposure to extrinsic factors generally require an additional selection procedure if reasonably pure cell lineages are to be obtained (Wiles and Johansson, 1999). Therefore, more refined methods are required to achieve a directed differentiation and increase the specificity and homogeneity of cell populations produced by exogenous gene delivery. Successful genetic manipulation of mES cells by the optimization of transfection conditions and promoter system has been reported (Bugeon et al., 2000; Ward and Stern, 2002). Moreover, mES cells have been successfully differentiated into quite directed and specified cell lineages by introducing individual genes for various soluble factors, signaling molecules and transcription factors that are implicated in particular differentiation pathways (Gra- 
tsch and O'Shea, 2002; Ishizaka et al., 2002).

The hES cells were found to be genetically modifiable via homologous recombination or by stable transgene expression, albeit with an extremely low transfection efficiency (Zwaka and Thomson, 2003). However, there have been very few reports of transient delivery and stable integration of exogenous genes in hES cells, using either chemical or electroporation methods. In this study, differentiated hES cells expressing both mesodermal and ectodermal markers were first derived using a defined medium and the differentiated hES cells were electroporated with a hEF1 $\alpha$ promoter-driven EGFP or human Noggin expression vector to enhance the transfection efficiency and maintain stable expression of exogenous genes in hES cells.

\section{Materials and Methods}

\section{Cell culture}

hES cells (SNUhES3; Lee et al., 2003), grown on a layer of immortalized mouse embryonic fibroblast (MEF) were cultured in DMEM/F12 (Life Technologies, Paisley, UK) supplemented with $20 \%$ knockout serum replacement, $0.53 \mathrm{mM} \beta$-mercaptoethanol, 0.1 $\mathrm{mM}$ non-essential amino acids (NEAA), $4 \mathrm{ng} / \mathrm{ml} \mathrm{bFGF}$, $50 \mathrm{IU}$ penicillin and $50 \mu \mathrm{g} / \mathrm{ml}$ streptomycin (all from Life Technologies). The colonies were mechanically dissociated into small pieces using a glass pipette and subcultured every 5 days. Human embryonic carcinoma (hEC, NCCIT) and immortalized MEF cells (American Type Cell Collection) were grown in DMEM supplemented with $10 \%$ fetal bovine serum (FBS, Hyclone, Logan, UT), and 50 IU penicillin and 50 $\mu \mathrm{g} / \mathrm{ml}$ streptomycin.

\section{Embryoid body formation and differentiation of hES cells}

Embryoid bodies (EBs) were formed by dissociating undifferentiated hES cells using a glass pipette and cultured in suspension in DMEM supplemented with $10 \%$ FBS on pluronic F-127 (Sigma)-coated $60-\mathrm{mm}$ petri-dishes (BD Biosciences, Bedford, MA) for 13 days. The EBs were replated in DMEM/F12 with N2 supplements composed of $30 \mathrm{nM}$ sodium selenite, $100 \mu \mathrm{M}$ putrescine, $20 \mathrm{nM}$ progesterone, $100 \mu \mathrm{g} / \mathrm{ml}$ BSA, $100 \mu \mathrm{g} / \mathrm{ml}$ apo-transferrin, and $5 \mu \mathrm{g} / \mathrm{ml}$ insulin (all from Sigma, St. Louis, MO; Chung et al., 2000) on $0.2 \%$ gelatin-coated tissue culture dishes, following which they were cultured for 40 days. Differentiated hES cells were maintained in DMEM/F12 supplemented with $20 \%$ FBS, $1 \mathrm{mM} \beta$-mercaptoethanol, $0.1 \mathrm{mM}$ NEAA, $50 \mathrm{IU} / \mathrm{ml}$ penicillin and $50 \mu \mathrm{g} / \mathrm{ml}$ streptomycin and subcultured every 5 to 6 days.

\section{Plasmid constructs}

The $h E F 1 \alpha$ promoter region was obtained from the pTracer-EF/V5-His A vector (Invitrogen, Carlsbad, CA) and replaced with the cytomegalo-virus (CMV) promoter region of $p$ EGFP-N3 (Clontech, Palo Alto, CA) or pIRES2-EGFP (Invitrogen). CMV immediate early enhancer $\left(\mathrm{CMV}_{\mathrm{IE}}\right)$ and chicken $\beta$-actin $(\mathrm{CBA})$ promoter regions were obtained from the pCAGGS vector (Kim et al., 1998) and replaced with the CMV promoter region of pEGFP-N3 or pDsRed2-N1 (Clontech; Figure 1A). Human Noggin hNoggin open reading frame was amplified from the genomic DNA of hEC cells, since the Noggin gene comprises one exon. The PCR product was cloned into a pCMV-c-myc tagging expression vector (Stratagene). Human Noggin tagged with c-myc was digested with restriction enzymes and inserted into the pIRES2-EGFP vector, following the replacement of its CMV promoter with the hEF1 $\alpha$ promoter. The hNoggin coding region was confirmed by DNA sequence analysis.

\section{Transfection}

Colony-formed undifferentiated hES cells were cotransfected with $5 \mu \mathrm{g}$ modified EGFP and PCBADsRed2 expression vectors by using FuGENE 6 transfection reagent (Roche, Indianapolis, IN) according to the manufacturer's recommendations, after partially removing feeder cells. Differentiated hES cells were transfected with $20 \mu \mathrm{g}$ modified EGFP or hNoggin expression vector by electroporation using a Bio-Rad Gene Pulser at $200 \mu \mathrm{F}$ and $320 \mathrm{~V}$, and se-

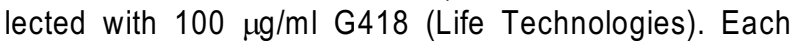
independent clone of transfected hES cells was initially cultured in one well of a $0.2 \%$ gelatin-coated 48 well plates and clones were subsequently propagated in $60-\mathrm{mm}$ tissue culture dishes for further analysis.

\section{RT-PCR}

Total RNAs were extracted from transfected and untransfected hES using Trizol reagent (Invitrogen). Reverse transcription was carried out using Superscript II (Invitrogen) and oligo-dT primers (Promega, Madison, WI) with incubation at $42^{\circ} \mathrm{C}$ for $1 \mathrm{~h}$ and $72^{\circ} \mathrm{C}$ for $15 \mathrm{~min}$. PCR reactions for hNoggin were performed using an $i$-taq premix kit (Intron, Seoul, ROK) with the following conditions: 1 cycle at $94^{\circ} \mathrm{C}$ for 5 min followed by 35 cycles at $94^{\circ} \mathrm{C}$ for $30 \mathrm{~s}, 55^{\circ} \mathrm{C}$ for $30 \mathrm{~s}, 72^{\circ} \mathrm{C}$ for $1 \mathrm{~min}$ and a final extension at $72^{\circ} \mathrm{C}$ for $15 \mathrm{~min}$. The PCR reactions for OCT4, NANOG, $\alpha$-fetoprotein (AFP), $\alpha$-cardiac actin and neurofilament (NF) $68 \mathrm{kDa}$ were performed under the following conditions: 1 cycle at $94^{\circ} \mathrm{C}$ for $3 \mathrm{~min}$ followed by 30 cycles at $94^{\circ} \mathrm{C}$ for $45 \mathrm{~s}, 55^{\circ} \mathrm{C}$ for OCT4, $57^{\circ} \mathrm{C}$ for NANOG, $60^{\circ} \mathrm{C}$ for AFP and NF $68 \mathrm{kDa}$, and $65^{\circ} \mathrm{C}$ 
Table 1. Oligonucleotide primers used for RT-PCR and expected product sizes.

\begin{tabular}{|c|c|c|}
\hline Target & Sequences & Product size (bp) \\
\hline \multirow[t]{2}{*}{ Noggin } & F: 5'-TAATGGATCCATGGAGCGCTGCCCCAGCCTAG-3' & 771 \\
\hline & R: 5'-GCAGAAGCTTCTAGCACGAGCACTTGCACTCG-3' & \\
\hline \multirow[t]{2}{*}{ ОСТ4 } & F: 5'-CGTGAAGCTGGAGAAGGAGAAGCTG-3' & 249 \\
\hline & R: 5'-CAAGGGCCGCAGCTTACACATGTTC-3' & \\
\hline \multirow[t]{2}{*}{ NANOG } & F: 5'-CCGAGAATTCATGAGTGTGGATCCAGCTTGTCC-3' & 917 \\
\hline & R: 5'-TGCTGTCGACTCATCTTCACACGTCTTCAGGTTG-3' & \\
\hline \multirow[t]{2}{*}{ AFP } & F: 5'-GCTGGATTGTCTGCAGGATGGGGAA-3' & 216 \\
\hline & R: 5'-TCCCCTGAAGAAAATTGGTTAAAAT-3' & \\
\hline \multirow[t]{2}{*}{$\alpha$-cardiac actin } & F: 5'-GGAGTTATGGTGGGTATGGGTC-3' & 486 \\
\hline & R: 5'-AGTGGTGACAAAGGAGTAGCCA-3' & \\
\hline \multirow[t]{2}{*}{$\mathrm{NF} 68 \mathrm{kDa}$} & F: 5'-GAGTGAAATGGCACGATACCTA-3' & 473 \\
\hline & R: 5'-ТTCСТСТССТTСТTСАССТTC-3' & \\
\hline \multirow[t]{2}{*}{$\beta$-actin } & F: 5'-TGGCACCACACCTTCTACAA-3' & 500 \\
\hline & R: 5-GCACAGCTTCTCCTTAATGT-3 & \\
\hline \multirow[t]{2}{*}{ GAPDH } & F: 5'-TGGTATCGTGGAAGGACTCA-3' & 250 \\
\hline & R: 5'-CCTGCTTCACCACCTTCTTG-3' & \\
\hline
\end{tabular}

for $\alpha$-cardiac actin (annealed depending on specific primer described in Table 1) for $30 \mathrm{~s}, 72^{\circ} \mathrm{C}$ for 45 $\mathrm{S}$ and a final extension at $72^{\circ} \mathrm{C}$ for $7 \mathrm{~min}$. Human $\beta$-actin and GAPDH were used as internal controls.

The PCR products were electrophoresed in a $1.2 \%$ agarose gel and visualized by ethidium bromide staining.

\section{Immunocytochemistry and alkaline phosphatase staining}

Cells were fixed in $3.7 \%$ paraformaldehyde (Sigma) solution, washed, and stored at $4^{\circ} \mathrm{C}$ in PBS (Life Technologies). Nonspecific antibody binding was blocked with $1 \%$ bovine serum albumin (BSA; Sigma) or $5 \%$ goat serum (Gibco) for $1 \mathrm{~h}$ at room temperature and then cells were exposed to primary antibodies: anti-cmyc (Santa Cruz, 1:100; Santa Cruz, CA), followed by secondary antibody, mouse IgG conjugated to Rhodamine (Chemicon, 1:1000), and anti-stage specific embryonic antigens (SSEA)-1, 3, 4 (Santa Cruz, 1:10, $1: 25,1: 50)$, followed by their respective secondary antibodies (mouse $\lg \mathrm{M}$, rat $\lg \mathrm{M}$ or mouse $\lg \mathrm{G}$ conjugated to FITC; Jackson Lab, 1:200). The cells were observed under a fluorescence microscope. Alkaline phosphatase (AP) activity was detected histochemically by incubation with AP substrate (Sigma) for $15 \mathrm{~min}$ at room temperature as described by the manufacturer's protocol.

Cells were photographed with a Nikon digital camera and images were imported into Adobe Photoshop 6.0.

\section{Results}

Transient expression of EGFP driven by different promoters in undifferentiated hES cells

To determine an optimal promoter system in hES cells, we constructed EGFP expression vectors driven by $C M V, C B A$ and $h E F 1 \alpha$ promoters, and used the pCBA-DsRed2 expression vector as a transfection efficiency control. Undifferentiated hES cells were cotransfected with the individual promoter-driven EGFP expression vectors and the pCBA-DsRed2 vector, using FuGENE 6. While all promoters employed appeared to drive the transcriptional activities of EGFP, none could maintain stable gene and protein expression upon subsequent passage (Figure 1B). On the contrary, hEC cells transfected with the same constructs did maintain stable expression of EGFP over several rounds of subculture (Figure $1 \mathrm{C}$ ). Although quantitative analysis of EGFP expression under different promoters was not conducted here, the hEF1 $\alpha$ promoter system showed qualitatively the most consistent reporter gene expression under fluorescence microscopy and was therefore used for further experiments.

\section{Development and characterization of differentiated hES cells}

In an effort to increase transfection efficiency and promote stable transgene integration, we derived differ- 


\begin{tabular}{|c|c|}
\hline & CMV \\
\hline CMV $_{\text {IE }}$ & CBA \\
\hline CMV $_{\text {IE }}$ & CBA \\
\hline
\end{tabular}

B
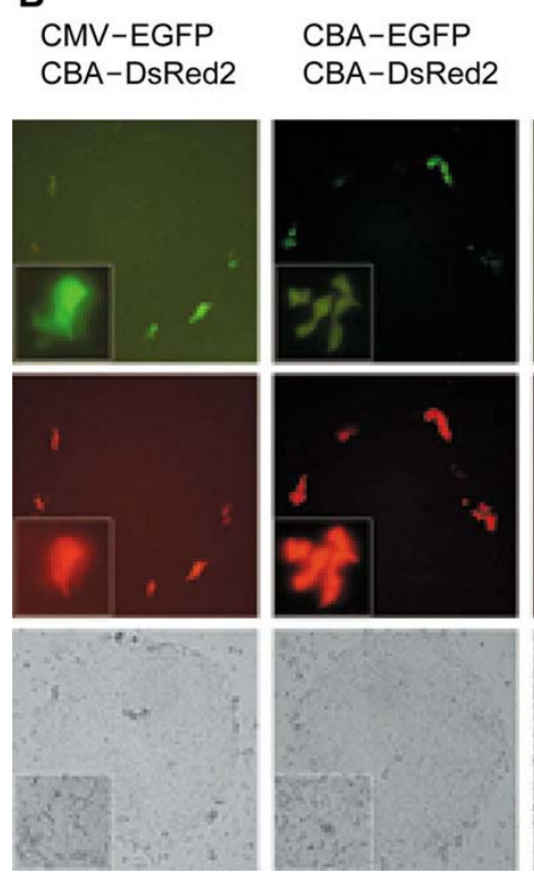

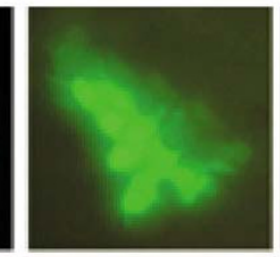

hEF $1 \alpha-E G F P$

CBA-DsRed2
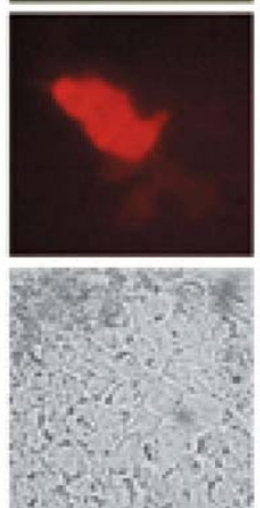
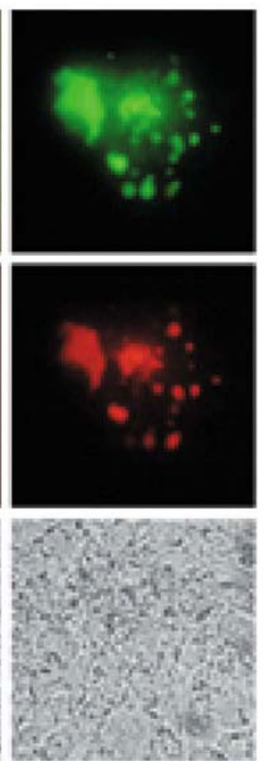

C
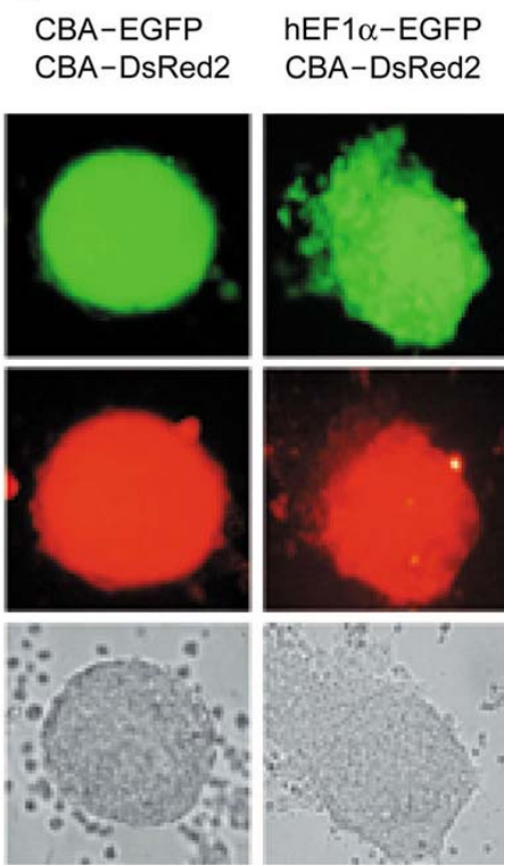

Figure 1. Transient and stable expression of EGFP driven by different promoters in undifferentiated $h E S$ and $h E C$ cells. (A) Modification of plasmid constructs with the individual promoters CMV, hEF1 $\alpha$ or CBA fused to the coding region of EGFP. The pCBA-DsRed2 vector was used as an internal control of transfection efficiency. (B) Transient expression of EGFP driven by the CMV, CBA or hEF1 $\alpha$ promoters in undifferentiated hES cells on partially removed feeder cells. (C) Stable expression of EGFP by CBA and hEF1 $\alpha$ promoters in $\mathrm{hEC}$ cells, presented as a transfection control.

entiated hES cells and characterized their gene/protein expression by RT-PCR, AP staining and immunocytochemistry.

To obtain the differentiated hES cells, undifferentiated hES cells grown in hES culture medium (Figure $2 \mathrm{~A})$ were dissociated into small pieces using a glass pipette and cultured in suspension for 13 days to form heterogeneously differentiated EBs (Figure 2B). The EBs were replated on $0.2 \%$ gelatin-coated tissue culture dishes and further cultured for 40 days in N2supplemented DMEM/F12 (Figure 2C). Following this, an apparently homogenous population of differentiated hES cells was selected under a phase contrast microscopy and subcultured every 5 to 6 days (Figure 2D).

RT-PCR analysis (Figure $3 A$ ) indicated that the ex- pression of OCT4 and NANOG, known markers of undifferentiated cells, were also expressed in differentiated hES cells. Both $\alpha$-cardiac actin (mesodermal marker) and NF $68 \mathrm{kDa}$ (ectodermal marker) were also detected, but AFP (endodermal marker) was undectable in differentiated hES cells. This result suggested that the differentiated hES cells still comprise a heterogeneous cell population, including cells destined to follow mesodermal or ectodermal lineages. Moreover, all three germ layer markers were detected in undifferentiated hES cells (Figure $3 \mathrm{~A}$ ). Differentiated hES cells did not express surface markers such as SSEA-3 and -4 or AP activity, while undifferentiated hES cells showed clear expression of SSEA-3 and -4 , as well as AP activity (Figure $3 B$ and $3 C$ ). 


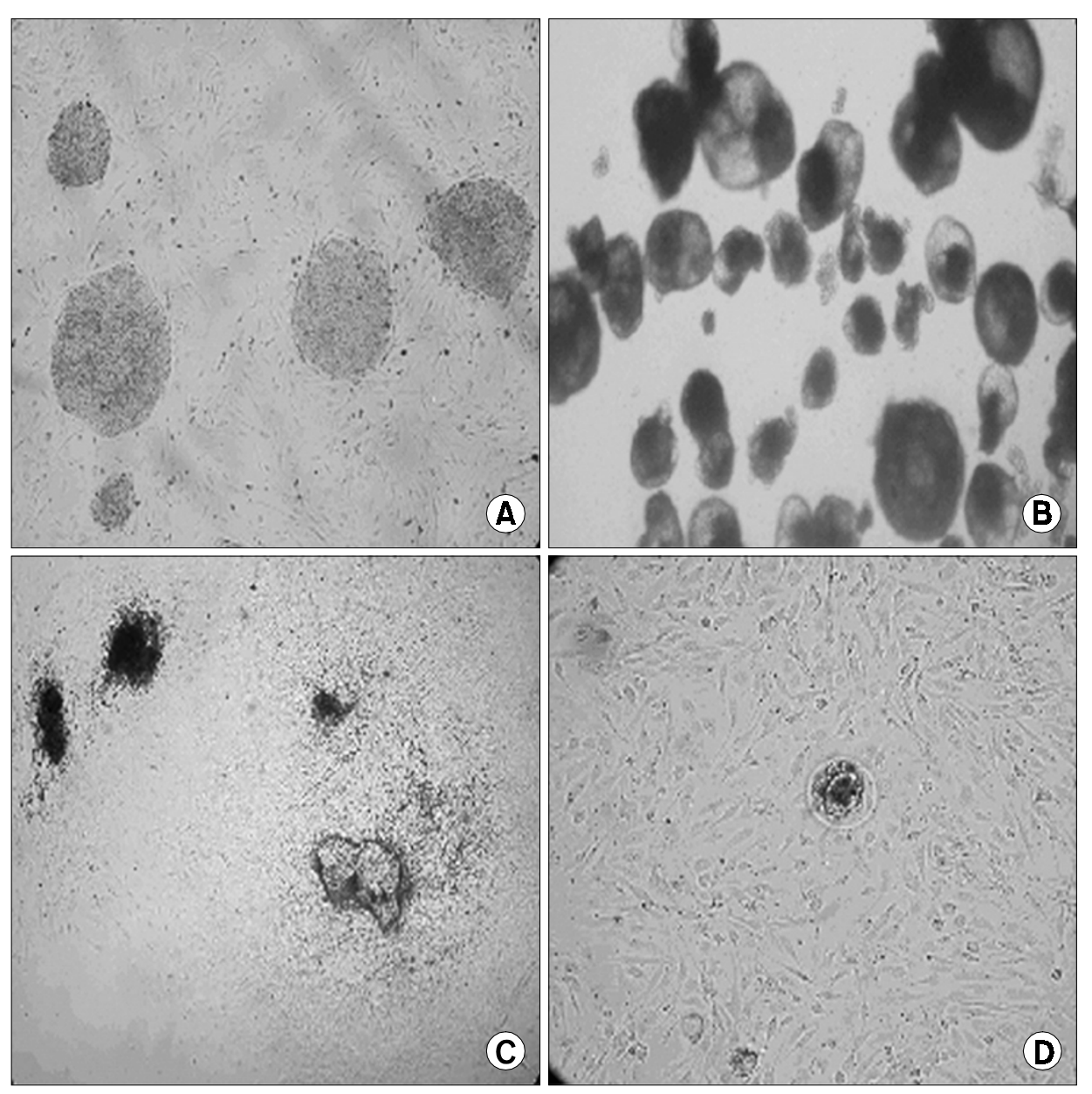

Figure 2. Establishment of a differentiated hES cell line. (A) Stage 1: undifferentiated $\mathrm{hES}$ cells were grown in hES culture medium. (B) Stage 2: EB was formed by dissociation of undifferentiated hES cells using a glass pipette and cultured in suspension for 13 days. (C) Stage 3: EBs were replated on $0.2 \%$ gelatin-coated tissue culture dishes and cultured for 40 days. (D) Stage 4: homogenous population of differentiated $\mathrm{hES}$ cells was selected under a phase contrast microscopy, grown further and subcultured every 5 to 6 days.

\section{Transfection of differentiated hES cells and stable expression of EGFP driven by the $h E F 1 \alpha$ promoter}

To investigate whether differentiated hES cells can be genetically modified by stably expressing an exogenous gene, we transfected these cells and undifferentiated $\mathrm{hES}$ cells with the $\mathrm{hEF} 1 \alpha$ promoter-driven EGFP expression vector (Figure 4A) by electroporation with $320 \mathrm{~V}$ and $200 \mu \mathrm{F}$. Stable expression of EGFP in differentiated hES cells was maintained in repeated subcultures selected with $100 \mu \mathrm{g} / \mathrm{ml} \mathrm{G418} \mathrm{(Figure} \mathrm{4B).}$ However, undifferentiated hES cells failed to maintain EGFP expression upon subculture (data not shown).

\section{Stable expression of exogenous $\mathrm{hNoggin}$ in differentiated hES cells}

To determine whether an exogenous functional gene, noggin, which is known to be a neuroectodermal inducer in mES cells (Gratsch and O'Shea, 2002), can be integrated and stably expressed in differentiated hES cells, we constructed a hEF $1 \alpha$ promoter-driven hNoggin bicistronic expression vector in which an in- ternal ribosome entry site was conjugated with the EGFP coding region (Figure 5A). Given that differentiated hES cell characteristically express ectodermal and mesodermal markers, but not an endodermal marker, electroporation with $320 \mathrm{~V}$ and $200 \mu \mathrm{F}$ and selection with $100 \mu \mathrm{g} / \mathrm{ml} \mathrm{G418}$ were used to stably transfect the hNoggin expression vector. The EGFPexpressing clones potentially containing exogenous hNoggin, were obtained by drug selection (Figure 5B).

Gene and protein expression in these transfected, differentiated hES cells was verified by RT-PCR and immunocytochemistry, respectively (Figure 6). RTPCR analysis revealed stronger expression of the hNoggin gene in transfected than untransfected hES cells, compared to the internal control, $\beta$-actin (Figure $6 \mathrm{~A})$. Strong c-myc epitope tagged hNoggin expression was observed immunocytochemically in the cytoplasm, as well as in the nucleus, of transfected, differentiated hES cells, although a lower, endogenous level of c-myc protein was also detected in both transfected and untransfected hES cells (Figure 6B). These results suggest that the existence of $c-m y c$ tagged hNoggin in the cytoplasm, as well as in the 

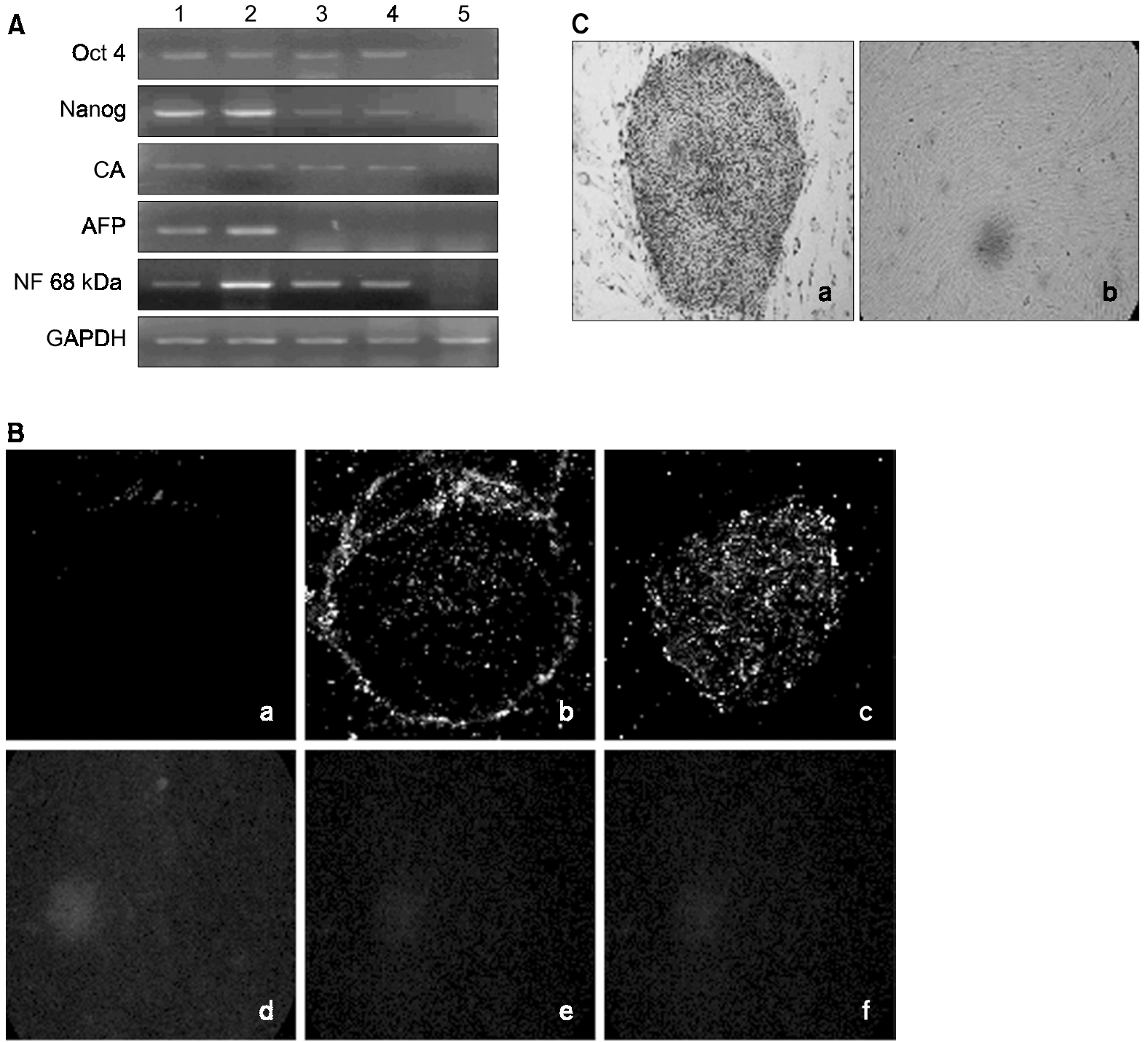

Figure 3. Characterization of a differentiated hES cell line by RT- PCR and immunocytochemistry and alkaline phosphatase staining analysis. (A) Detection of undifferentiated and germ layer specific markers by RT-PCR analysis. Lane 1: undifferentiated hES cell. Lane 2: day 4 EB derived from undifferentiated $h E S$ cells. Lane 3: differentiated hES cell. Lane 4: $E B$ reformed from differentiated hES cell. Lane 5: immortalized MEF cells. CA; $\alpha$-cardiac actin, AFP; $\alpha$ - fetoprotein, NF $68 \mathrm{kDa}$; neurofilament $68 \mathrm{kDa}$. (B) Detection of undifferentiated surface markers by immunocytochemistry. a-c: undifferentiated hES cells. d-f: differentiated hES cells. a, d; SSEA-1, b, e; SSEA-3 and c, f; SSEA-4. (C) Detection of AP activity. a; undifferentiated hES cells, b; differentiated hES cells.

nucleus, may reflect overexpression of exogenous hNoggin driven by the hEF1 $\alpha$ promoter.

\section{Discussion}

Despite numerous investigations on the pluripotency and indefinite propagation capabilities of ES cells, genetic modification of hES cells has proven to be a technical challenge, although mES cells are genetically modifiable. Recently, human immunodeficiency virus type 1 lentiviruses were reported to be an ef- ficient tool for exogenous gene delivery and stable expression of transgenes in hES cells (Gropp et al., 2003). However, lentiviruses may present complications caused by the host immune response and therefore constitute a risk for clinical applications such as gene therapy and regenerate medicine (Bencheikh et al., 1999). To optimize transfection conditions without the risks associated with viral delivery, we investigated several commercially available chemical transfection reagents as well as electroporation techniques. Undifferentiated hES cells were transiently transfected, using several different transfection ragents (lipo- 

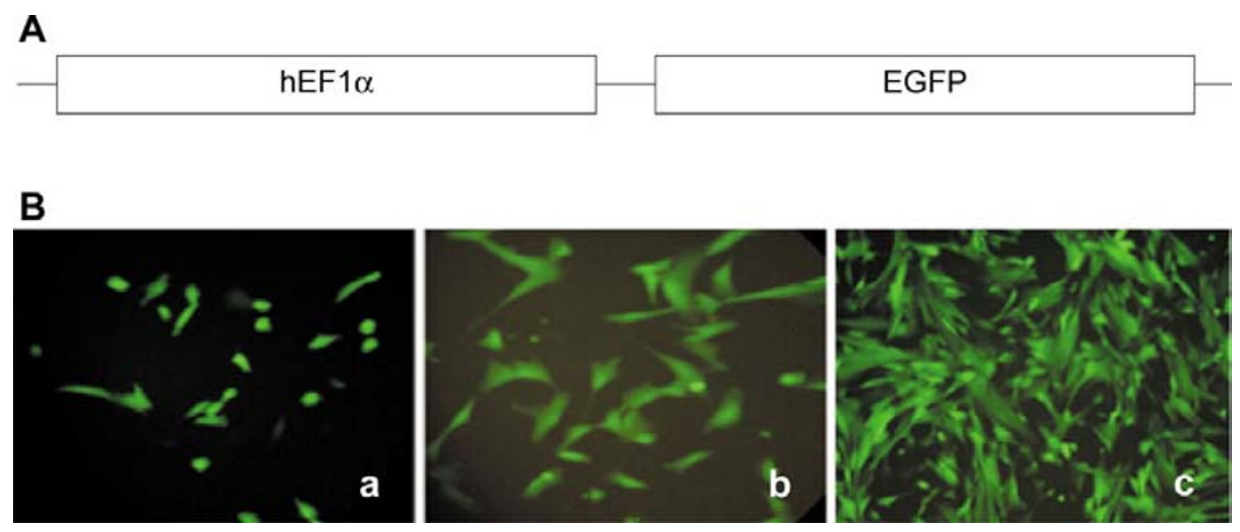

Figure 4. Establishment of stable cell lines expressing EGFP in differentiated hES cells. (A) hEF1 $\alpha$ promoter-driven EGFP expression vector. (B) Transfection of differentiated $\mathrm{hES}$ cell and stable expression of EGFP with $100 \mu \mathrm{g} / \mathrm{ml}$ G418 selection. a; 7 days, b; 10 days, c; 14 days following drug selection.

A
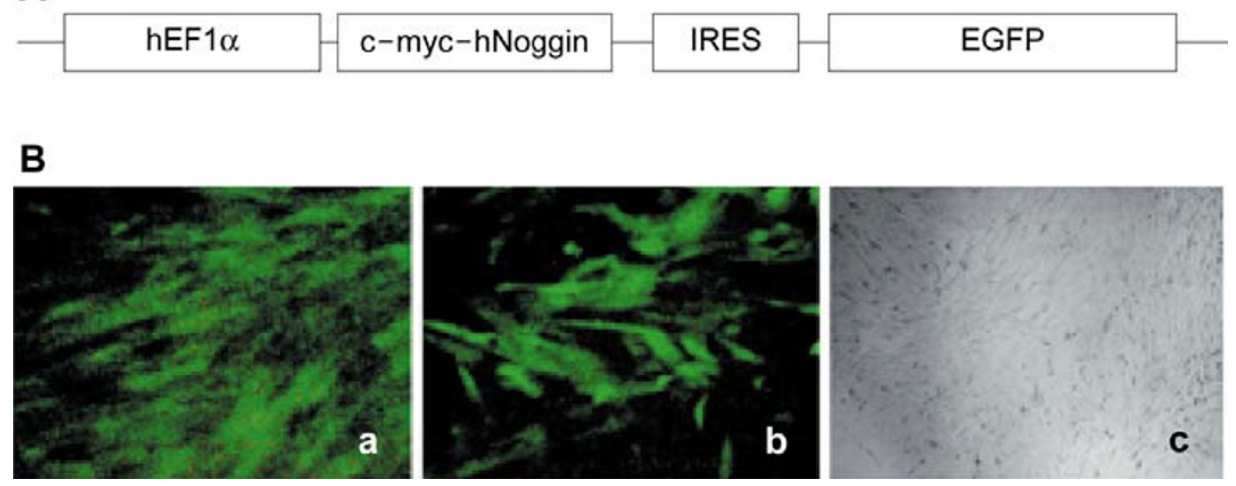

Figure 5. Stable expression of EGFP in differentiated hES cells transfected with hNoggin gene. (A) Modification of bicistronic plasmid constructs driven by $h E F 1 \alpha$ promoter with the coding region of EGFP and hNoggin. (B) Fluorescence microscopic observation of EGFP expression in differentiated hES cells transfected with hNoggin expression vector. a: $100 \mathrm{X}, \mathrm{b}$ : 200X, c: Phase contrast (100X).

fectamine plus, FuGENE 6, ExGen 500) or electroporation, with a CBA-driven EGFP expression vector, and EGFP expression was detected by fluorescence microscopy. Of the reagents tested, FuGENE 6 produced the most constant expression of the reporter gene in our hES cells (data not shown). On the basis of this preliminary data, several different promoter systems were also tested using FuGENE 6. While all three promoters, CMV, $h E F 1 \alpha$ and CBA, drove the transcriptional activities of EGFP, we found it impossible to maintain stable expression of a reporter gene upon subsequent passage of undifferentiated hES cells. This was in contrast to the stable transgene expression observed with repeated subcultures of hEC cells, NCCIT (Figure 1).

The efficiency of drug-selectable transfection efficiency in hES cells was reported as low as about $10^{-5}$ by chemical reagents and substantially lower by electroporation (Zwaka and Thomson, 2003). In addition, undifferentiated ES cells were shown to have a tendency to propagate heterogeneously and differentiate into various cell types (Wiles and Johansson, 1999). Thus, the development of more defined differentiation systems is required in order to obtain specific and pure cell populations. In mES cells, many such strate- gies have been developed to increase the efficiency of specific differentiation events by genetic or nongenetic modification (Gratsch and O'Shea, 2002; Ishizaka et al., 2002; Kuai et al., 2003; Sachinidis et al., 2003; Takahashi et al., 2003). However, genetic manipulation of hES cells has proven to be technically difficult, reflecting inherent complexities in their culture systems and a limited supply of cells. Here, in an attempt to circumvent these technological problems and develop an efficient strategy for increasing transfection rate and stable transgene expression, we initially obtained differentiated hES cells expressing mesodermal and ectodermal markers by using a defined medium (Figure 2 and 3 ). When the differentiated hES cells were transfected with a hEF $1 \alpha$ promoter-driven EGFP expression vector by electroporation, genetic modification was easy to assess and stable expression of a reporter gene was obtained, even during prolonged culture. This result suggests that it might be more efficient to deliver exogenous genes to differentiated rather than undifferentiated hES cells, and that this may be used ultimately to drive more directed differentiation events and produce purer populations of specific cell types.

Differentiated hES cells were derived using a de- 


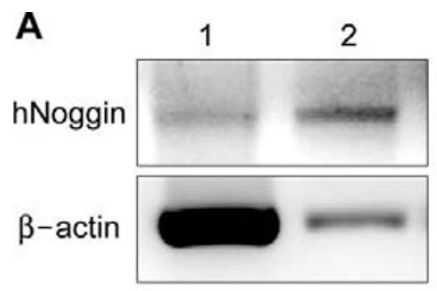

B
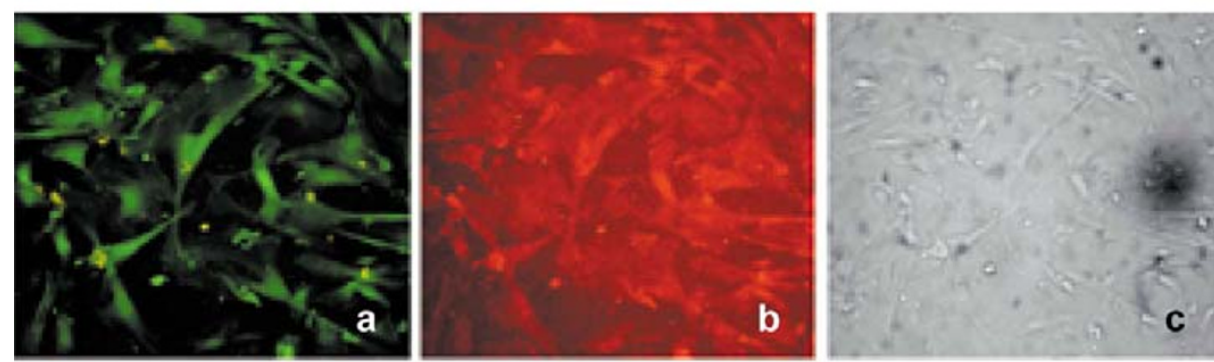

Figure 6. Verification of differentiated $\mathrm{hES}$ cells transfected with hNoggin. (A) hNoggin gene expression in hNoggin-transfected and untransfected differentiated hES cells by RT-PCR analysis. Lane 1: differentiated hES cell. Lane 2: hNoggin-trasnfected differentiated hES cell. Beta actin was used as an internal control. (B) Immunocytochemical analysis of c-myc epitope tagged hNoggin expression in differentiated hES cells by immunocytochemistry. a-c; hNoggin-transfected, d-f; non-transfected, a, d; EGFP expression, $b, e$; d

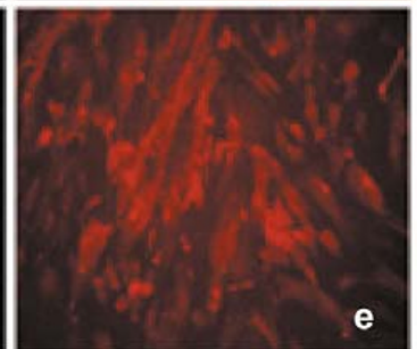
anti- c-myc, c, f; phase contrast.

fined medium. It has been reported that defined medium with N2 supplements is effective for neuronal differentiation, with this being mediated by a combination of induction factors (Yao et al., 1995). However, the differentiated hES cells cultured in modified $\mathrm{N} 2$ medium seem to comprise a heterogeneous cell population, as evidenced by their expression of both ectodermal and mesodermal marker genes (Figure $3 A)$. On the basis of these characteristics, we hypothesized that differentiated hES cells expressing both ectodermal and mesodermal markers could be more directed more effectively into specific differentiation pathways by delivering exogenous genes for extrinsic induction factors. We transfected these cells with hNoggin, a glycoprotein known to act as a neuronal inducer and antagonist for bone morphogenetic proteins (Wilson and Hemmati-Brivanlou, 1997). Exogenous noggin was reported to be successfully expressed in mES cells where it is able to drive rapid differentiation into a primitive neuronal phenotype (Gratsch and O'Shea, 2002). Here, we obtained the clones of hNoggin-expressing differentiated hES cells (Figure 6) and found that EGFP expression was maintained in repeated subcultures (Figure 5). Although no significant morphological differences were apparently observed between untransfected and transfected differ- entiated hES cells (data not shown), we did obtain a homogenous cell population that stably express exogenous hNoggin. However, further functional studies of hNoggin in hES cells are required, not least because cell-type specificities may exist regarding the effects and mechanisms of hNoggin in particular differentiation processes.

In conclusion, we here present an efficient strategy for increasing transfection rate and maintaining stable expression of exogenous transgenes in differentiated hES cells. This new approach may facilitate the genetic manipulation and selection of pure, specific hESderived cell population.

\section{Acknowledgement}

This research was supported by a grant (SC-11013) from Stem Cell Research Center of the 21st Century Frontier Research Program funded by the Ministry of Science and Technology, Republic of Korea.

\section{References}

Bencheikh M, Bentsman G, Sarkissian N, Canki M, Volsky DJ. Replication of different clones of human immunodefi- 
ciency virus type 1 in primary fetal human astrocytes: enhancement of viral gene expression by Nef. J Neurovirol 1999:5:115-24

Bugeon L, Syed N, Dallman MJ. A fast and efficient method for transiently transfecting ES cells: application to the development of systems for conditional gene expression. Transgenic Res 2000;9:229-32

Chung JJ, Cho SH, Kwon YK, Kim DH, Kim KJ. Activation of retinoic acid receptor $\mathrm{g}$ induces proliferation of immortalized hippocampal progenitor cells. Mol Brain Res 2000; 83:52-62

Gratsch TE, O'Shea KS. Noggin and chordin have distinct activities in promoting lineage commitment of mouse embryonic stem (ES) cells. Dev Biol 2002;245:83-94

Gropp M, Itsykson P, Singer O, Ben-Hur T, Reinhartz E, Galun E, Reubinoff BE. Stable genetic modification of human embryonic stem cells by lentiviral vectors. Mol Ther 2003; 7:281-7

Ishizaka S, Shiroi A, Kanda S, Yoshikawa M, Tsujinoue $H$, Kuriyama S, Hasuma T, Nakatani K, Takahashi K. Development of hepatocytes from ES cells after transfection with the HNF-3beta gene. FASEB J 2002;16:1444-6

Kim DK, Kojima M, Fukushima T, Miyasaka M, Nakauchi H. Engraftment of human myelodysplastic syndrome derived cell line in transgenic severe combined immunodeficient (TGSCID) mice expressing human GM-CSF and IL-3. Eur J Haematol 1998;61:93-9

Kuai $X L$, Cong XQ, Li XL, Xiao SD. Generation ofhepatocytes from cultured mouse embryonic stem cells. Liver
Transpl 2003;9:1094-9

Loebel DA, Watson CM, De Young RA, Tam PP. Lineage choice and differentiation in mouse embryos and embryonic stem cells. Dev Biol 2003;264:1-14

Sachinidis A, Fleischmann BK, Kolossov E, Wartenberg M, Sauer H, Hescheler J. Cardiac specific differentiation of mouse embryonic stem cells. Cardiovasc Res 2003;58:278-91

Takahashi T, Lord B, Schulze PC, Fryer RM, Sarang SS, Gullans SR, Lee RT. Ascorbic acid enhances differentiation of embryonic stem cells into cardiac myocytes. Circulation 2003:107:1912-6

Thomson JA, Itskovitz-Eldor J, Shapiro SS, Waknitz MA, Swiergiel JJ, Marshall VS, Jones JM. Embryonic stem cell lines derived from human blastocysts. Science 1998;282: 1145-7

Ward CM, Stern PL. The human cytomegalovirus immediateearly promoter is transcriptionally active in undifferentiated mouse embryonic stem cells. Stem Cells 2002;20:472-5

Wiles MV, Johansson BM. Embryonic stem cell development in a chemically defined medium. Exp Cell Res 1999;247:241-8

Wilson PA, Hemmati-Brivanlou A. Vertebrate neural induction: Inducers, inhibitors, and a new synthesis. Neuron 1997; 18:699-710

Yao M, Bain G, Gottlieb DI. Neuronal differentiation of P19 embryonal carcinoma cells in defined media. J. Neurosci Res 1995;41:792-804

Zwaka TP, Thomson JA. Homologous recombination in human embryonic stem cells. Nat biotechnol 2003;21:319-21 